distance very similarly to the case related by Mr. Griffith. One curious feature in the present instance was that the roots of the tree could be traced to a considerable distance by the earth above them being thrown up as over a mole barrow.

Most of the trees struck here have been oak; but there were also two poplars, four elms, a chestnut, and the fir above mentioned. It is said that beech-trees are never struck: probably the smooth close-fitting bark makes a better conductor than the rough bark of the oak.

Cranleigh, August 26.

\section{Nose-Blackening as a Preventive of Snow-Blindness.}

IN vol, xxxviii. of NATURE there were sereral interesting letters on this subject. Will you allow me to suggest a possible explanation?

For some years past I have interested myself in the choroidal circulation, and my observations have led me to believe that when light is absorbed by the choroidal pigment the blood. supply at that spot is increased. If the light is intense, this increase soon has the effect of blurring the image, and if at the same time the light is intense and the exposure to it prolonged, the sensitiveness of the retina may suffer for some time after from the same cause, i.c. an abnormally large blood-supply in the choroid.

In the comrse of the blood-vessels there is just such a connection between the retina and the skin as the nose-blackening preventive requires. My suggestion is that the blackening of the skin increases its clemand for blood in some way, perhaps by its increase of temperature, and that thus a larger supply is drawn aloug the main branches of the ophthalmic artery, the naso-frontalis, the supra-orbitalis, and the lacrymalis, diminishing the quantity which finds its way into the small and almost independent system of the choroid. In this way nose-blackening would save the retina from being oppressed and injured in the way mentioned.

I may mention that if anyone after walking for an hour or so in the snow covers his eyes so as to exclude all external light, he will find his eyes filled with a very bright retinal light, and also if he is at all accustomed to see the blood corpuscles moving in his field of vision he will see them at such a time very distinctly and in great numbers by looking at the sky.

The theory which my observations have led me to form, that there is a very intimate connection between the retinal light and the circulation in the choroid is almost necessarily crippled by the fact that it rests largely upon subjective phenomena which are misleading, are not demonstrable, and depending on the constitution of the subject are not readily confirmed. Until, therefore, I can hear of another worker in the same field whose observations agree in the main with my own, I do not feel prepared to publish them.

Jena, Aurgust.

\section{A Method of Mounting Dried Plants.}

AN example of a very useful and expeditious method of mounting herbarium specimens adopted here is inclosed as worthy of attention. Short strips of lead, used in packing tea, are passed through slits in the paper on each side of the part of the plant to be fastened, and the ends then bent flat out on the back of the sheet. The many advantages of using this, or some other pliable metal, in certain cases, are very obvious. Has this method been hitherto suggested? JOHN WILSON.

University, St. Andrews.

COLOUR-BIINDNESS AND DEFECTIVE FARSIGHT AMONG THE SEAMEN OF THE MERCANTILE MARINE.

I $N$ the House of Commons, recently, attention was called to this subject by Dr. Farquharson, who, in stating that he would take an early opportunity of discussing it next session, intimated that the efficiency of the Board of Trade regulations on this matter was open to grave suspicion. On making inquiry, we find his doubts are only too well founded. When, in the year
I 852 , the carrying of red and green side-lights by sailing vessels was made compulsory, the subject of colourblindness had not awakened the attention of practical observers. Had the fact that from 3 to 4 per cent. of the whole male population are colour-blind then been known, it is possible that some mode other than by showing red and green lights would have been devised to indicate the positions of vessels at sea at night. As there is generally but a hazy conception of what is meant by the term colour-blind, we will briefly indicate its exact significance.

When, in 1794 , the distinguished chemist, Dalton, published a description of his sense of colour, the scientific world were surprised to find that there existed individuals whose perception of colour differed in a remarkable way from that of their fellow-man. To have said that an individual possessed the sense of sight was tantamount to saying that he possessed the sense of colour, the latter being considered an integral part of the former ; but Dalton's report clearly showed that the two senses were separate and distinct, and that, while an individual might have a perfect appreciation of form, he might also be quite unable to perceive any distinction between two or three or more distinct and different colours. Further investigation showed that there were a few people who could discern no colour at all, every object appearing as black or white, or as shades of black and white (grey). This is total colour-blindness, and is very rare. The usual form, and that which we allude to when we speak of a colourblind, is that in which the individual can distinguish the colours blue and yellow, but can see no difference between the colours red, green, and brown; and from the fact that one of these individuals, if given a vivid scarlet skein of wool, will select to match with it green skeins and brown skeins, it follows that he must see green and scarlet as he sees brown. Now, there being between 3 and 4 per cent. ${ }^{1}$ of the whole male population afflicted with this variety, it follows that a very large section of the community are by nature disqualified for all those positions in which the correct interpretation of coloured lights is essential to safety. Clear as this fact must be, it was not until Dr. George Wilson, of Edinburgh, in the year I 855 , published his admirable work, entitled "Researches on Colour-blindness," that public attention was invited to the subject. He showed with the greatest clearness how the safety of a vessel lay in the hands of men-"look-outs," officers, and pilots-who might be colour-blind, but were unconscious of this defect, or afraid to confess it ; and he came to the definite conclusion, as the colour-blind were in a minority in the community, therefore, those destined to deal with signals should be selected solely from the majority whose vision was normal, and he earnestly urged upon those in authority the necessity of excluding colour-blind men from the sea profession.

One sentence was prophetic, that in which he says "the appalling yearly list of lost vessels which appears in our Wreck Returns awakens the suspicion that more than one of these fatal disasters may have resulted from the mistaken colour of a lighthouse beacon or harbour lamp, which on a strange coast, and with the accompaniments of a snow-storm or a thick fog, has been wrongly deciphered by a colour-blind pilot." ${ }^{\circ}$ And if true of the pre-steamship days when vessels carolled along at the rate of a few miles an hour, what is to be said of the present time, when our "greyhounds" of the ocean flash along at the rate of twenty miles an hour, day and night? The regulation red and green lights of a steamer are

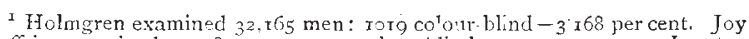
Jeffries examined $r o, 387$ men : $43 \mathrm{~T}$ colour-blind $-4{ }^{\circ} 49$ per cent. London Cummittee examined 14,846 men : 617 c slour-blind -4 . 56 per cent.

Colcur-bindiness proved to be the cause of Lmmberman and Isaac bell collision: ten lives lost. Colour-blindness proved to be the cause of los; of City of Anstin-colour of buoys was mistaken : money loss $£ 40,003$. Colourblindness or defective sight was the cause of collision between Carbet Castle and $f$. H. hanior: money loss frgoo. 